\title{
Urolitíase em caprinos e ovinos ${ }^{1}$
}

\author{
Franklin Riet-Correa ${ }^{2}$, Sara V.D. Simões ${ }^{2}$ e Jackson S.Vasconcelos ${ }^{2}$
}

\begin{abstract}
Riet-Correa F., Simões S.D.V. \& Vasconcelos J.S. 2008. [Urolithiasis in sheep and goats.] Urolitíase em ovinos e caprinos. Pesquisa Veterinária Brasileira 28(6):319-322. Hospital Veterinário, CSTR, Universidade Federal de Campina Grande, Patos, PB 58700-000, Brazil. E-mail: franklin.riet@pq.cnpq.br

Urolithiasis is a common disease in the Brazilian semiarid in rams and bucks fed with grains, mainly with low C:P ratio. From 28 rams with urolithiasis sent to the Veterinary Hospital of the Federal University of Campina Grande, Paraíba, 19 died and 9 survived, and from the bucks, 13 died and 3 survived At necropsy the main lesions were presence of calculi in the urethra and urinary bladder, diffuse purulent urethritis, hemorrhagic necrotizing urethritis, rupture of the urethra with presence of urine in the subcutaneous tissue, hydronephrosis, urinary bladder rupture, necrotizing diffuse nephritis, pyelonephritis, renal hemorrhage, and renal rupture. The severity of the lesions is responsible for the high case fatality rate despite medical and chirurgic treatment. The most important preventive measure is the correction of the $\mathrm{Ca}: \mathrm{P}$ ratio to at least $2: 1$. The administration of good quality roughage in the food is also necessary. In cases in which the amount of concentrate food is higher than 1.5\% live weight, the addition of $1 \%$ ammonium chloride and $0.5-4 \%$ of sodium chloride in the diet could be also necessary. Water had to be offered ad libitum. It is necessary to abolish the use of ad libitum mineral supplementation in sheep and goats fed grains or their byproducts.
\end{abstract}

INDEX TERMS: Urolithiasis, grain feeding, phosphorous, phosphorus:calcium rate.

RESUMO.- A urolitíase é uma doença freqüente no semiárido em ovinos e caprinos alimentados com grãos, principalmente quando a relação $\mathrm{Ca}: P$ não é corrigida e são utilizadas grandes quantidades de concentrado. De 28 ovinos com urolitíase atendidos no Hospital Veterinário da UFCG, 19 morreram e 9 receberam alta, dos 15 caprinos 12 morreram e 3 receberam alta. As alterações mais freqüentes foi presença de cálculos na uretra e bexiga, uretrite hemorrágica difusa severa, uretrite purulenta, ruptura de uretra com presença de urina no tecido subcutâneo, cistite hemorrágica necrosante, ruptura de bexiga, hidronefrose, nefrite necrosante difusa, abscesso renal, pielonefrite, hemorragia renal e ruptura renal. A gravidade das lesões observadas justifica a alta letalidade ape-

\footnotetext{
${ }^{1}$ Recebido em 26 de dezembro de 2007.

Aceito para publicação em 8 de janeiro de 2008.

${ }^{2}$ Hospital Veterinário, CSTR, Universidade Federal de Campina Grande (UFCG), Patos, PB 58700-000. *Autor para correspondência: franklin.riet@pq.cnpq.br
}

sar dos tratamentos medicamentosos e cirúrgicos. A medida preventiva mais importante é a correção dos níveis de Ca e P. Recomenda-se, também, a administração de volumosos em boa quantidade e qualidade e, nos casos em que a quantidade de concentrados seja superior a $1,5 \%$ do peso vivo, a administração de cloreto de amônia a 1\% no concentrado e a administração de cloreto de sódio em concentrações de 0,5 até $4 \%$. Deve ser administrada água de boa qualidade à vontade. É necessário abolir a prática, extremamente utilizada em caprinos e ovinos, de administrar sal mineral em animais alimentados com grãos e subprodutos dos mesmos.

TERMOS DE INDEXAÇÃO: Urolitíase, alimentação com grãos, fósforo, relação Ca:P.

\section{INTRODUÇÃO}

O processo patológico caracterizado pela presença de cálculos ou concreções no sistema urinário é denominado urolitíase. A doença torna-se importante clinicamente 
em ruminantes quando os cálculos causam obstrução do trato urinário, que normalmente ocorre na uretra (Radostits et al. 2000). A ruptura da uretra ou da bexiga ocorrerá em 2-3 dias se a obstrução não for aliviada. Os urólitos ocorrem em animais de qualquer sexo, mas a obstrução raramente ocorre em fêmeas devido à uretra curta, sem flexões e de maior diâmetro. A flexura sigmóide, a curvatura isquiática e o processo uretral dos ovinos e caprinos constituem os locais mais comuns para os urólitos se alojarem e causar obstrução. Ovinos e caprinos castrados em idade precoce são mais susceptíveis, por terem menor desenvolvimento da uretra, que é de menor calibre que a uretra de animais não castrados.

\section{Etiologia}

$\mathrm{Na}$ etiologia da urolitíase vários fatores afetam a taxa de formação do urólito, tais como a concentração de um determinado soluto na urina; a facilidade com que o soluto se precipita na solução; a presença de um núcleo (matriz orgânica); e a tendência das concreções a se precipitar. (Radostits et al. 2000).

Ruminantes alimentados com grãos ou seus subprodutos são mais predispostos a urolitíase devido ao fato destes terem níveis de fósforo superiores ao de cálcio, o que leva a proporção de cálcio/fósforo da dieta a níveis de 1:1 ou menores. Nessas condições formam-se urólitos de estruvita (fosfato de amoniamagnésio hexaidratado). Dietas ricas em magnésio também favorecem a formação desses cálculos. A concentração de mucoproteínas da urina, que ajudam a formar o núcleo orgânico dos cálculos, é aumentada por rações ricas em concentrados e pobres em volumosos. A peletização parece aumentar, também, os riscos de formação de cálculos, se a ração já apresenta tendência para tal (Radostits et al 2000). A peletização é um processo mecânico, onde ocorre a aglomeração de pequenas partículas através do calor úmido e da pressão de uma prensa. No processo ocorre desagregação dos grânulos de amilose e amilopectina facilitando a ação enzimática, e nas proteínas ocorre uma alteração nas estruturas terciárias facilitando a digestão das mesmas.

A saliva é importante, também, no metabolismo do fósforo, pois apresenta uma concentração de fósforo 12 a 16 vezes maior do que o sangue. Os ruminantes removem o fósforo do organismo pela sua excreção pela saliva e daí para o rúmen e fezes. Normalmente, cerca de $60 \%$ do $P$ que chega ao rúmen é proveniente da saliva e os $40 \%$ restantes vêm da dieta. Dietas altas em concentrados e baixas em volumosos diminuem a formação de saliva, em conseqüência mais fósforo deve ser eliminado pelo rim e excretado na urina aumentando o risco de urolitíase (Anderson 2007).

Outras causas de urolitíase, não observadas no nordeste, incluem o pastejo em solo ricos em sílica causando urólitos de sílica e dietas ricas em cálcio que podem produzir urólitos de carbonato de cálcio. Quando um grande número de animais é comprometido é provável que algum outro fator, como a deficiência de vitamina $\mathrm{A}$ ou a administração de estrogênio seja a causa de excessiva descamação epitelial, favorecendo a formação do núcleo e a deposição de cristais ao redor do mesmo. Animais em pastagens de Trifolium subterraneum ou outras pastagens estrogênicas podem ter urolitíase devido à descamação que os estrogênios causam no epitélio do sistema urinário. As células de descamação funcionam como uma matriz orgânica, parte integrante da maioria dos tipos de cálculos. Plantas tais como o Halogeton spp. ou as partes superiores da beterraba açucareira podem induzir a formação de cálculos de oxalato de cálcio (Radostits et al. 2000).

Os primeiros sinais da urolitiase geralmente são anorexia e meteorismo, o que pode confundir o clínico no momento da primeira observação. Posteriormente observam-se depressão, bruxismo, dor abdominal, pateamento dos membros anteriores e balançar da cauda, anúria ou passagem de algumas gotas de urina coradas com sangue após grande esforço para urinar, dor à palpação da região peniana, taquicardia, taquipnéia e vasos espisclerais congestos.

Nos casos de necrose da uretra e ruptura da bexiga há escapamento de urina para o tecido conjuntivo da parede abdominal ventral e prepúcio ou cavidade abdominal causando irritação do tecido, necrose, reabsorção de urina e uremia. A ruptura da bexiga com liberação de grandes volumes de urina na cavidade abdominal é evidenciada por diminuição da dor e distensão do abdômen o qual toma forma de pêra ocorrendo em seguida sinais de desidratação e uremia.

\section{Urolitíase no semi-árido}

A urolitíase é uma doença importante no semi-árido (Brandão e Riet-Correa 2006). Entre janeiro de 2001 e novembro de 2007 chegaram ao Hospital Veterinário (HV) da UFCG, em Patos, Paraíba, 43 animais com urolitíase. Todos machos não castrados, sendo 28 ovinos e 15 caprinos, com idade variando de 70 dias a 5 anos. Todos os animais eram alimentados com alimentos concentrados. Muitos ingeriam ração comercial balanceada a qual era agregada grãos ou subprodutos (milho, farelo de trigo, farelo de soja). Sete produtores informaram que administravam sal comum e 5 administravam sal mineral. Dois produtores administravam 1\% de cloreto de amônia na ração. Um fator observado na maioria dos casos dos animais que chegaram ao HV era que estes já haviam sido submetidos à exérese do processo uretral ou tentativa de remoção do cálculo mediante sondagem da uretra.

Dos 28 ovinos atendidos 19 morreram e 9 receberam alta, dos 15 caprinos 12 morreram e 3 receberam alta. Os ovinos e caprinos mortos por urolitíase representaram $5,77 \%$ e $2,9 \%$ dos 329 e 413 ovinos e caprinos necropsiados, respectivamente, durante o período. As alterações macroscópicas mais freqüentes foram presenças de cálculos na uretra e bexiga, uretrite hemorrágica difusa severa, uretrite purulenta, ruptura de uretra com presença 
de urina no tecido subcutâneo, cistite hemorrágica necrosante, ruptura de bexiga, hidronefrose, nefrite necrosante difusa, abscesso renal, pielonefrite, hemorragia renal e ruptura renal.

Os 12 animais que se recuperaram, apresentavam obstrução parcial da uretra (9) ou obstrução do processo uretral (3) e foram tratados no HV com analgésicos, antiinflamatórios, antibióticos, fluidoterapia, e realizada a exérese do apêndice vermiforme quando necessária.

A casuística do Hospital Veterinário da UFCG mostra que a doença tem uma alta letalidade. Perante essa realidade a recomendação mais adequada de tratamento é a de intervir cirurgicamente imediatamente após os primeiros sinais. Em caso do cálculo estar no apêndice vermiforme a recuperação é rápida e eficiente, no entanto deve se ter cuidado com a possibilidade de recidiva. No caso de cálculos no $S$ peniano ou na curvatura isquiática a solução mais eficiente é a implantação de uma sonda na bexiga para eliminação de urina e cálculos da mesma até que houvesse a recuperação das lesões da uretra o que permitiria após alguns dias restituir a eliminação de urina pela uretra e a eliminação do(s) cálculo(s). Um problema é que os animais chegam ao HV quando já apresentam lesões irreversíveis do sistema urinário e se esta intervenção é tardia a recuperação é muito difícil em conseqüência da presença dessas lesões. Em 4 casos de urolitíase obstrutiva foi realizada cistotomia com implantação de sonda de Foley na bexiga. Um animal morreu e três foram eutanasiados, dois devido à ruptura de uretra após o início dos procedimentos de fechamento da sonda iniciados uma semana após a realização da intervenção e um devido a suspeita de septicemia. Uma das causas desta alta mortalidade é a demora no atendimento dos animais. Na Universidade da Califórnia, de 94 casos de urolitíase que ingressaram ao hospital, anorexia e meteorismo foram os sinais iniciais mais freqüentes (Metre 2007). Pelo contrário, no HV todos os animais que ingressam já apresentavam sinais evidentes de obstrução urinária, o que reflexa a demora no atendimento e a diminuição das chances de recuperação.

Atualmente como protocolo de tratamento para urolitíase obstrutiva no HV se estabeleceu que inicialmente é feita uma sedação do animal com acepromazina para exposição e avaliação do pênis e observação se a obstrução é no processo uretral realizando-se a exérese deste se for necessário. A seguir faz-se uma tentativa de restabelecimento do fluxo urinário com o uso de relaxante muscular, analgésicos, antiinflamatórios e antibióticos, especialmente em casos de obstrução parcial da uretra. Aguardam-se aproximadamente 12 horas, não havendo indícios de recuperação realiza-se a cistotomia e implantação da sonda de Foley. Caso o proprietário já tenha realizado procedimentos como a passagem de sonda ou exérese do processo uretral e sejam observados danos a glande ou uretra o único procedimento realizado é a uretrostomia perineal e após recuperação o animal é enviado para o abate.

\section{Profilaxia}

Em conseqüência da alta letalidade da doença é evidente que a única forma de evitar as perdas por urolitíase é mediante a profilaxia. Para isto o mais importante é assegurar que a relação $\mathrm{Ca}: \mathrm{P}$ da dieta seja de no mínimo $2: 1$. O grave problema é que a grande maioria dos produtores cujos rebanhos tem problema de urolitíase, além da ração comercial, que deve ter uma relação $\mathrm{Ca}: \mathrm{P}$ adequada, administram diversos grãos e subprodutos dos mesmos sem corrigir a relação Ca:P. Por outro lado, nos produtores de animais para venda como reprodutores a prática de administrar grandes quantidades de grãos, mais de $1,5 \%$ do peso vivo, agrava ainda mais o problema.

Como norma podemos recomendar que os produtores administrem $1 \%$ ou no máximo $1,5 \%$ do peso vivo em concentrado e que esse concentrado tenha uma relação Ca:P de, no mínimo 2:1. Para obter esta relação sempre que os animais sejam alimentados com grãos ou seus subprodutos deve ser agregado aos mesmos 1,5\% de carbonato de cálcio (calcáreo calcítrico ou farinha de ostra). Devemos lembrar que os grãos devem ser suplementados com $\mathrm{NaCl}$ na quantidade de $0,25-0,5 \%$. Desta forma a profilaxia da urolitíase será eficiente. A administração de maiores concentrações de $\mathrm{NaCl}$ do que a recomendada para suprir as necessidades poderá, também, ajudar na profilaxia da doença. Pode-se administrar até $4 \%$ de cloreto de sódio na ração, mas deve-se considerar que concentrações muito altas podem diminuir o consumo de alimento. Sempre que se agregar sal na ração deve ser administrado água a vontade. O mecanismo para ação preventiva do cloreto de sódio é o efeito diurético, diluindo as substâncias formadoras de cálculos e aumentando a solubilidade das substâncias urinárias. No caso dos animais estarem recebendo quantidade adequada de concentrados é importante fornecer a mesma em várias administrações ao dia, pois administrações únicas de grandes quantidades ocasionam aumento marcante na concentração de sais na urina favorecendo o desenvolvimento de urólitos. A administração de volumosos de boa qualidade e quantidade diminui o risco de urolitíase, entre outras coisas por que favorece a produção de saliva.

Por outro lado devemos considerar que muitos produtores, principalmente aqueles de animais para serem comercializados como reprodutores (animais de pista), utilizam quantidades de concentrados muito maiores do que as recomendadas, aumentando significativamente $o$ risco de urolitíase. Nestes casos, além de ser imprescindível a mistura de carbonato de cálcio nos grãos utilizados podemos recomendar a utilização de cloreto de amônia a $1 \%$ na ração, que impede a formação do cálculo por diminuir o pH urinário e evitar a precipitação dos fosfatos. No entanto devemos considerar que a adição de cloreto de amônia não evita a urolitíase se a relação Ca:P é inadequada.

No caso de alto risco de urolitíase por alimentação com quantidades excessivas de grãos é aconselhável não administrar rações peletizadas. 
Sob nenhuma hipótese deve ser oferecido sal mineral a animais alimentados com grãos e subprodutos, pois este contém minerais que podem ser tóxicos: fósforo que causa urolitíase e, em caprinos, osteodistrofia fibrosa; cobre que causa intoxicação em ovinos; e magnésio que causa urolitíase (Riet-Correa 2004). O sal mineral é um suplemento para animais a campo. Em animais recebendo concentrados os minerais devem ser suplementados misturados ao concentrado e os únicos necessários são $\mathrm{Na}$, Ca, e selênio. Este último na concentração de 2,2mg de selenito de sódio por kg de ração (Riet-Correa 2007).

\section{REFERÊNCIAS}

Anderson D.E. 2007. Small Ruminant Urolithiasis. http://www.acvs.org/ AnimalOwners/HealthConditions/FoodAnimalTopics/
SmallRuminantUrolithiasis/. Consultado em 9 de dezembro de 2007.

Brandão L. \& Riet-Correa F. 2006. Urolitíase em pequenos ruminantes no semi-árido da Paraíba. Semi-Árido em Foco, Patos, 2(1):92-98.

Metre D.S. 2007. Urolithiasis in Small Ruminants: surgical and dietary management. http://www.aasrp.org/hot_topics/2004/August\%202004/ Urolithiasis/Cornell\%20Urolith\%20Surgery\%2004.doc. Consultado em 10 de dezembro de 2007.

Radostits O.M., Gay C.C., Blood D.C. \& Hinchcliff K.W. 2000. Clínica Veterinária: um tratado de doenças dos bovinos, ovinos, suínos, caprinos e eqüinos. 9a ed. W.B. Saunders, London, p.441-447.

Riet-Correa F. 2004. Suplementação mineral em pequenos ruminantes no semi-árido. Ciência Veterinária nos Trópicos, Recife, 7 (2/3):112130.

Riet-Correa F. 2007. Suplementação mineral em ruminantes, p.263-280. In: Riet-Correa F., Schild A.L., Lemos R.A.A. \& Borges J.R.J. (ed.), Doenças de Ruminantes e Eqüídeos. Vol.2. Pallotti, Santa Maria, RS. 